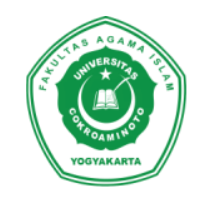

Ulumuddin: Jurnal Ilmu-ilmu Keislaman

P-ISSN: 1907-2333 E-ISSN: 2685-9211

https://jurnal.ucy.ac.id/index.php/agama_islam

Volume 10 Nomor 2, Desember 2020, h. 87 - 102

\title{
KEKERASAN SIMBOLIK DALAM PENDIDIKAN ISLAM JENJANG IBTIDATYAH DI INDONESIA
}

\author{
Hamam Fitriana ${ }^{*}$ ) \\ 1)Magister Pendidikan Guru Madrasah Ibtidaiyah \\ FITK UIN Sunan Kalijaga Yogyakarta \\ hamamfitriana@gmail.com \\ *Penulis Koresponden \\ \begin{tabular}{|l|l|l|}
\hline Diajukan: 12-9-2020 & Diterima: 28-9-2020 & Diterbitkan: 29-12-2020 \\
\hline
\end{tabular}
}

\begin{abstract}
Some textbooks still contain forms of violence. There is a type of violence that is latently perpetuated or reproduced as a habit of social and cultural structures which is called symbolic violence. In textbooks, how are forms of symbolic violence perpetuated or reproduced through language, namely in sentences and images. As a descriptive-analytic research library, the researcher tries to analyze the integrated thematic textbook 2013 curriculum for SD/MI which contains gender class distinctions between male and female classes. The distinction of gender classes in textbooks is then described and described by researchers and then analyzing sentences and images that contain symbolic violence. In the sentences in the textbook, there is a male class dominance, namely there are 62 sentences or $61.8 \%$ sentences while the female class is only 40 sentences or $39.2 \%$ sentences. In the picture, the male class dominates, namely there are 78 pictures or $65 \%$, while the female class as the dominant class has 42 sentences or $35 \%$ pictures. The results showed that the male class dominates the female class in sentences and pictures. Male class domination is a form of socialization of the dominant class habitus to the dominated class. The socialization of the dominant class habitus is carried out in order so that the habits of social and cultural structures can be perpetuated or reproduced so that they are accepted as things that are justified and imitated. This in Pierre Bourdieu's language is said to be symbolic violence.
\end{abstract}

Keywords: symbolic violence, textbook, madrasah ibtidaiyah

Abstrak: Beberapa buku ajar tingkat madrasah ibtidaiyyah dan setara masih mengandung bentuk kekerasan. Ada jenis kekerasan yang secara laten dilanggengkan atau direproduksi sebagai kebiasaan struktur sosial dan budaya yang dinamakan sebagai kekerasan simbolik. Dalam buku ajar, bagaimana bentuk kekerasan simbolik dilanggengkan atau direproduksi melalui bahasa yakni pada kalimat dan gambar. Sebagai penelitian library research yang bersifat diskriptif-analitik, peneliti mencoba menganalisi buku ajar tematik terpadu kurikulum 2013 untuk SD/MI yang di dalamnya mengandung distingsi kelas gender antar kelas laki-laki dan kelas perempuan. Distingsi kelas gender dalam buku ajar kemudian peneliti uraikan dan diskripsikan lalu menganalisis pada kalimat dan gambar yang mengandung kekerasan simbolik. Pada kalimat 
dalam buku ajar terdapat dominasi kelas laki-laki yakni terdapat 62 kalimat atau 61,8\% kalimat sedangkan kelas perempuan hanya 40 kalimat atau 39,2\% kalimat. Pada gambar kelas laki-laki mendominasi yakni terdapat 78 gambar atau $65 \%$, sedangkan kelas perempuan sebagai kelas terdominasi terdapat 42 kalimat atau 35\% gambar. Hasil penelitian menunjukkan adanya dominasi kelas laki-laki terhadap kelas perempuan pada kalimat dan gambar. Dominasi kelas laki-laki merupakan bentuk sosialisasi habitus kelas dominan terhadap kelas yang terdominasi. Sosialisasi habitus kelas dominan dijalankan dalam rangka agar kebiasaan struktur sosial dan budaya dapat dilanggengkan atau direproduksi sehingga diterima sebagai hal yang dibenarkan dan diimitasi. Hal tersebut dalam bahasa Pierre Bourdieu dikatakan sebagai kekerasan simbolik.

Kata Kunci: kekerasan simbolik, buku ajar, madrasah ibtidaiyah

\section{A. Pendahuluan}

Fenomena kekerasan yang dialami anak usia sekolah sampai sekarang masih menjadi pekerjaan rumah yang tidak kunjung usai termasuk dalam pendidikan Islam. Berbagai bentuk kekerasan dari kekerasan fisik hingga kekerasan verbal pada anak yang telah muncul di Indonesia.

Di Jawa Tengah, jumlah kekerasan berdasarkan semua jenis kekerasan yang dialami oleh anak (o-18 tahun) pada tahun 2019 mencapai 757. ${ }^{1}$ Usia anak merupakan usia untuk memperoleh pendidikan. Data Komisi Perlindungan Anak Indonesia (KPAI) tahun 2019 menyebutkan bahwa berdasarkan jenjang pendidikan, mayoritas kasus kekerasan terjadi di jenjang SD dan yang sederajat, termasuk Ibtidaiyah, yaitu sebanyak 25 kasus atau mencapai 67 persen. ${ }^{2}$

Kekerasan juga tidak dikehendaki dalam Pendidikan Islam di Indonesia. Lingkungan keluarga berperan besar dalam penanaman jiwa anti kekerasan seperti pendidikan kewirausahaan yang menjadikannya

\footnotetext{
1 Badan Pusat Statistik Provinsi Jawa Tengah, “Jumlah Kekerasan berdasarkan Jenis Kekerasan yang Dialami oleh Anak (Usia 0-18 Tahun) Korban Kekerasan di Provinsi Jawa Tengah, 2019," diakses September 1, 2020, https://jateng.bps.go.id/ statictable/2020/07/21/1913/jumlah-kekerasan-berdasarkan-jenis-kekerasan-yangdialami-oleh-anak-usia-o-18-tahun-korban-kekerasan-di-provinsi-jawa-tengah-2019.html.

2 Rega Maradewa, "KPAI: 67 Persen Kekerasan Bidang Pendidikan Terjadi di Jenjang SD,” diakses September 1, 2020, https://www.kpai.go.id/berita/kpai-67-persenkekerasan-bidang-pendidikan-terjadi-di-jenjang-sd.
} 
sebagai awal penanaman bagi anak. ${ }^{3}$ Namun pendidikan madrasah tidak bisa berpangku tangan karena sebagai satu bentuk lembaga pendidikan Islam tingkat dasar yang penting. Sejak pra-kemerdekaan telah bersanding sejajar dengan pesantren dan sekolah dengan konsep masingmasing. ${ }^{4}$ Apalagi posisinya di awal-awal pendidikan dasar, sehingga butuh stimulan untuk bisa berdampak terhadap emosi para peserta didiknya.5

Pendidikan Agama Islam di madrasah tingkat ibtidaiyah memiliki tujuan yang disampaikan oleh Wahyudin dalam Nugraha untuk menumbuhkembangkan iman dengan cara penanaman, penghayatan dan pengamalan siswa sesuai keyakinannya. Tholhah dari sumber yang sama pun menegaskan hal senada dalam uraian yang lebih detil. Semua itu dimaksudkan untuk mewujudkan manusia Indonesia yang taat beragama dan berakhlak mulia, yaitu manusia yang berpengetahuan, rajin beribadah, cerdas, produktif, bertoleransi (tasamuh), menjaga keharmonisan secara personal dan sosial serta mengembangkan budaya agama dalam komunitas sekolah. ${ }^{6}$

Tujuan demikian bisa terealisasi bila pembelajaran di tingkat dasar itu mengembalikan kepada Quran yang menghendaki pendidikan anti kekerasan. Hal itu bisa ditelusuri dari beberapa ayatnya, antara lain; AliImran (3): 1592; Al-Ma’idah (5): 324; Al-Anbiya'(21): 107; Al-Fath (48): 293. Dalam sekolah perlu penciptaan rasa aman dan damai, terlindung dari kekerasan. Segala permasalahan dan perbedaan yang ada bisa diselesaikan dengan cara yang diterima oleh semua pihak, pengelola, pendidik, terdidik, melalui musyawarah untuk mencapai kesepakatan

3 Fattah Setiawan Santoso, "Lingkungan Keluarga Sebagai Awal Pengembangan Kewirausahaan Islam," Nuansa Akademik Jurnal Pembangunan Masyarakat 5, no. 1 (2020): 13-22.

4 Taufik Nugroho, “Analisis Manajemen Pendidikan Terhadap Kualitas Madrasah Indonesia," Ulumuddin: Jurnal Ilmu-ilmu Keislaman 6, no. 2 (2016): 80-87.

5 Rozib Sulistiyo, "Pengembangan Kecerdasan Emosional Bagi Siswa Kelas Awal Madrasah Ibtidaiyyah Pada Pembelajaran Bahasa Indonesia," Ulumuddin: Jurnal Ilmuilmu Keislaman 7, no. 1 (2017): 45-58.

6 Muhamad Tisna Nugraha, "Pendidikan Agama dan Kekerasan pada Anak (Child Abuse) Perspektif Pendidikan Islam," Raheema 2, no. 1 (2015): 56-65; Arum Yuli Dwi Rahmawati, Muh Nasruddin, dan Imroatun Imroatun, "Peran Sosial Guru Pendidikan Agama Islam Di Wilayah Pesisir Utara Pulau Jawa," Nuansa Akademik Jurnal Pembangunan Masyarakat 5, no. 1 (Juni 16, 2020): 1-12. 
tanpa kekerasan.7 Hukuman di pegangan suci umat Islam itu tidak harus dimaknai dengan kekerasan fisik. Rubini mencontohkan pemberian sentuhan siswa yang melakukan pelanggaran berupa kalimat-kalimat bijaksana. ${ }^{8}$ Jauhari kemudian memaparkan metode pendidikan lain dalam Quran yang tidak mengarahkan kepada kekerasan, yaitu; metode hikmah, mauizah, jidal. Semua itu dapat dilakukan dengan penuh rasa kasih sayang tanpa mengandung unsur kekerasan ataupun paksaan. 9 Munif dan Aisya menawarkan enam perkataan penting sebagai prinsip komunikasi pendidikan dalam Quran untuk menghindari kekerasan. Qaul Sadida (An-Nisa'(4):9); Qaul Balig (An-Nisa'(4):63); Qaul Ma'ruf (AlBaqarah (2): 235, An-Nisa'(4): 5, Al-Ahzab (33): 32); Qaul Karim (AlIsra'(17):23); Qaul Layin (Thaha (20): 44); Qaul Maisur (Al-Isra'(17): 28). ${ }^{10}$

Jalan kekerasan dalam pendidikan Islam bukan lagi pilihan, namun dalam kenyataan masih terjadi. Di pendidikan Islam tingkat dasar juga masih terjadi dalam pelbagai relasi antara pendidik, peserta didik, kebijakan, hingga pembelajaran. Salah satunya adalah buku ajar yang menjadi rujukan peserta didik justru menjadi arena kekerasan.

Beberapa kasus dalam buku ajar yang mengandung unsur kekerasan telah muncul. Di Jombang terdapat buku pelajaran agama Islam yang berisi materi bahwa orang musyrik boleh dibunuh. ${ }^{11}$ Buku “Anak Islam Suka Membaca” karangan Nurani Musta’in, terbitan Pustaka Amanah, Solo, Jawa Tengah pada cetakan 2013, terdapat kata dan kalimat yang mengandung unsur kekerasan dalam buku tersebut. Sehingga

7 Rubini, "Pendidikan Anti Kekerasan Dalam Al-Qur'an," Al-Manar Jurnal Komunikasi dan Pendidikan Islam 7, no. 2 (Desember 30, 2018): 133-152.

8 Eva Setya Rini, "Pendidikan Anti Kekerasan Terhadap Anak Berdasarkan Perspektif Islam (Al-Qur'an Dan Al-Hadits)," in Prosiding Seminar Nasional STKIP Andi Matappa Pangkep, vol. 1, 2018, 136-145.

9 Muhammad Insan Jauhari, "Pendidikan Anti Kekerasan Perspektif Al-Qur'an Dan Implementasinya Dalam Metode Pengajaran PAI," Jurnal Pendidikan Agama Islam 13, no. 2 (April 24, 2017): 171-184.

1o Muhammad Munif dan Siti Aisah, "Six Medicine Qoulan Dalam Mengatasi Kekerasan Guru Terhadap Siswa Di Lembaga Pendidikan," Jurnal Inspiratif Pendidikan IX, no. 2 (Agustus 7, 2020): 35-52.

${ }_{11}$ Mukhtar Bagus, "Buku Agama Ajarkan Kekerasan, Banser Datangi Disdik Jombang," sindonews, diakses September 1, 2020, https://daerah.sindonews.com/ berita/980224/23/buku-agama-ajarkan-kekerasan-banser-datangi-disdik-jombang. 
Kemendikbud menerbitkan Surat Edaran Nomor 109/C.C2/DU/2016 Tentang Pelarangan Bahan Ajar PAUD Mengandung Unsur Kekerasan. ${ }^{12}$ Secara yuridis, dalam rangka preventif kekerasan di dunia pendidikan, dibuatlah Peraturan Menteri Pendidikan Dan Kebudayaan Republik Indonesia Nomor 82 Tahun 2015 Tentang Pencegahan Dan Penanggulangan Tindak Kekerasan Di Lingkungan Satuan Pendidikan.

Fakta kekerasan pada kata dan kalimat di atas yang secara eksplisit telah ditemukan dalam buku ajar pada lembaga pendidikan Islam Indonesia. Belum lagi buku ajar yang secara implisit melahirkan kekerasan. Bentuk tersirat inilah yang secara halus tidak disadari oleh masyarakat, pendidik, dan peserta didik namun bisa berdampak di kemudian hari pada diri anak.

Kekerasan demikian dalam bahasa Pierre Bourdieu disebut sebagai kekerasan simbolik. Bentuk kekerasan itulah yang bersifat laten sehingga korban tidak menyadarinya. Mekanisme simbolik ini menyembunyikan kekerasan sehingga tidak dikenali dan tidak dirasakan sebagai sebuah bentuk kekerasan oleh pihak yang menjadi sasaran. ${ }^{13}$

Ada beberapa penelitian dalam buku ajar yang hasilnya memastikan penemuan terhadap adanya kekerasan simbolik. Pada buku ajar PAI MI yakni dengan adanya dominasi kelas atas (kaya) 60 persen terhadap kelas bawah (miskin) 32 persen dalam teks dan gambar. ${ }^{14}$ Pada buku BSE Sekolah Dasar dari 660 halaman yang memuat habitus kelas, sebagian besar ditampilkan adalah habitus kelas atas sebesar 90 persen, dan sebagian kecil adalah habitus kelas bawah sebesar 10 persen. ${ }^{15}$

Kekerasan simbolik yang terjadi karena ada habitus kelas dominan yang disosialisasikan dalam pelbagai ranah pendidikan termasuk buku

12 Rega Maradewa, "ajarkan kekerasan pada anak buku ini dilarang beredar," 2016, diakses September 1, 2020, https://poskotanews.com/2016/01/22/ajarkankekerasan-pada-anak-buku-ini-dilarang-beredar/.

13 Dewi Suryanti, "Kekerasan Simbolik Tayangan Drama Seri Korea Terhadap Perilaku Remaja Asrama Putri Kabupaten Kutai Timur”, eJournal Sosiatri/Sosiologi, vol. 4, no. 2 (2016), h.4.

${ }_{14}$ M. Sofyan Al-Nashr, "Kekerasan Simbolik dalam Buku Pelajaran Madrasah (Analisis Kritis Perspektif Pierre Bourdieu)" (Universitas Islam Negeri Sunan Kalijaga, 2014).

15 Nanang Martono, Kekerasan Simbolik di Sekolah: Sebuah Ide Sosiologi Pendidikan Pierre Bourdieu (Jakarta: Raja Grafindo Persada, 2012), h.49. 
ajar. Buku ajar secara implisit menanamkan nilai-nilai yang melahirkan disparitas antar kelas. Jarak tersebut lahir karena tidak ada ekuilibrium relasi antara kelas dalam kontruksi sosial dan budaya. Ketidakseimbangan ini menyebabkan kemunculan dari entitas kelas yang dominan dan yang terdominasi. Dominasi dalam kelas melalui buku ajar inilah yang secara tidak langsung melahirkan sebuah bentuk kekerasan simbolik.

Konsep bentuk simbolik muncul dari teori Pierre Bourdieu tentang habitus, arena, dan modal. Habitus adalah produk dari internalisasi struktur sosial. ${ }^{16}$ Di situ terjadi proses kognisi dari dunia luar yang kemudian di internalisasi yang akhirnya membentuk persepsi, pikiran, dan tindakan terhadap dunia sosial. Rupa arena bisa berbentuk konfigurasi hubungan-hubungan objektif antar berbagai posisi. ${ }^{17}$ Arena menjadi tempat pertarungan sekaligus perjuangan agen untuk melanggengkan budaya dan sosial agen. Modal merupakan sesuatu yang dianggap berharga dalam arena, digunakan sebagai sumber sekaligus tujuan dari strategi kekuasaan. Jika arena adalah tempat habitus menempuh strategi, modal adalah bagian dari mekanisme strategi habitus dalam menguasai arena. ${ }^{18}$

Kebanyakan kekerasan dalam pendidikan Islam masih dilihat dalam relasi pendidik dan terdidik. ${ }^{19}$ Rupa simbolik pun tak terkecualikan, seperti terlihat dalam penelitian Putri. ${ }^{20}$ Apalagi teks Quran memang istimewa saat menjelaskan pendidikan sebagai relasi pendidik dan terdidik seperti yang telah dijabarkan oleh Setiani dan Nadjih. ${ }^{21}$

${ }^{16}$ Goodman D.J. dan George Ritzer, Teori Sosiologi; dari Teori Sosiologi Klasik Sampai Perkembangan Mutakhir Teori Sosial Postmodern (Yogyakarta: Kreasi Wacana, 2017), h.581.

17 Pierre Bourdieu dan Loïc J.D. Wacquant, An Invitation to Reflexive Sociology (Cambridge: The University of Chicago Press, 1992), h.97.

18 Moch Najib Yuliantoro, Ilmu dan Kapital: Sosiologi Ilmu Pengetahuan Pierre Bourdieu (Yogyakarta: Penerbit Kanisius, 2016), h.16.

19 Rubini, "Pendidikan Anti"; Rini, "Pendidikan Anti"; Jauhari, "Pendidikan Anti"; Munif dan Aisah, "Six Medicine."

${ }_{20}$ Rina Oktafia Putri, "Praktek Kekerasan Simbolik (Relasi Guru dan Peserta didik dalam Pendidikan Islam)," Millah: Jurnal Studi Agama 17, no. 2 (April 5, 2018): 319-336.

${ }^{21}$ Nurul Fatihah dan Difla Nadjih, "Hubungan Pendidik Dan Terdidik Dalam AlQuran," Ulumuddin: Jurnal Ilmu-ilmu Keislaman 7, no. 2 (2017): 73-86. 
Hubungan keduanya sekarang juga difasilitasi dengan buku ajar. Kekerasan simbolik di dalamnya bahkan telah diteliti oleh al-Nashr, ${ }^{22}$ dan Martono. ${ }^{23}$ Keduanya masih insight buku ajar sebagai sosialisasi habitus kelas atas dan bawah atau kelas kaya dan miskin.

Sementara kekerasan tidak semata kekerasan ditimbulkan dari kesenjangan dalam kelas social ekonomi semata. Kekerasan bisa ditimbulkan oleh kesenjangan yang lebih melekat secara alamiah dalam gender lelaki dan perempuan. Dengan melihat melihat sosialisasi habitus kelas gender yakni kesenjangan di dalamnya turut andil dalam kemunculan kekerasan dalam pendidikan.

Bourdieu sendiri pertama kali memasuki diskusi sosiologis tentang hubungan gender pada tahun 1990 dengan esainya tentang male domination, kemudian direvisi sebagai sebuah buku pada tahun 1998. ${ }^{24}$ Teorinya tentang gender dalam habitus telah berhasil mengoreksi pandangan transformasi refleksif (theories of reflexive transformation) yang memprediksi berlebihan dalam melihat kemampuan seseorang yang hidup dalam pos-tradisional untuk membentuk kembali identitas, termasuk gendernya. Yang terdahulu itu bersikukuh pada gender sebagai identifikasi simbolik dibanding eksistensi yang mengakar dalam diri. Theory of embodiment Bourdieu melihat sebagai perbedaan kekuatan yang harus diterima sehingga bisa menjadi relasi positif. 25

Temuan Edgerton dkk. tentang perbedaan gender dalam dunia akademik mendukung keyakinan para pendahulunya yang berpihak pada Bourdieu. Mereka meneliti dengan memeriksa model struktur - disposisi praktek dari hubungan antara status sosial ekonomi keluarga, jenis kelamin, habitus, praktik akademik, dan prestasi akademik menggunakan data multilevel di negara Kanada. Penelitian mereka berhasil membuktikan teori Bourdieu tidak hanya canggih secara teoritis, tetapi

${ }_{22}$ Al-Nashr, "Kekerasan Simbolik dalam Buku Pelajaran Madrasah (Analisis Kritis Perspektif Pierre Bourdieu).”

23 Martono, Kekerasan Simbolik di Sekolah: Sebuah Ide Sosiologi Pendidikan Pierre Bourdieu.

24 Beate Krais dan Jennifer Marston William, "The Gender Relationship in Bourdieu's Sociology,” SubStance 29, no. 3 (2000): 53-66.

${ }^{25}$ Lois McNay, "Gender, Habitus and the Field: Pierre Bourdieu and the Limits of Reflexivity," Theory, Culture \& Society 16, no. 1 (1999): 95-117. 
juga berkelanjutan secara empiris sehingga ada jaminan dalam keberlangsungan pengembangan riset gender di masa depan. ${ }^{26}$

Adapun arena penelitian tentang kekerasan simbolik dalam ranah gender ini terdapat dalam buku ajar termasuk kalimat dan gambar yang ada padanya. Sedangkan model gender sebagai alat mekanisme kelas dominan melestarikan habitus mereka untuk dilanggengkan atau direproduksi dalam buku ajar.

\section{B. Metodologi}

Penelitian ini sangat sulit dikategorikan sebagai penelitian tindakan kelas, ${ }^{27}$ meski pembicaraan berkaitan situasi dan kondisi dalam kelas. Pilihan library research lebih tepat karena bersifat deskriptif-analisis yaitu data-data yang ada disusun dijelaskan dan kemudian dianalisis. ${ }^{28}$ Penelitian ini menguraikan kemudian menganalisisis terjadinya kekerasan simbolik dalam relasi gender yang terdapat dalam buku ajar pendidikan ibtidaiyah dalam bentuk kata dan gambar.

Data primer berupa buku tematik tingkat sekolah dasar yang disiapkan oleh pemerintah dalam rangka implementasi kurikulum 2013. Penulis: Angi St. Anggari, Afriki, Dara Retno Wulan, Nuniek Puspitawati, Lely Mifthachul Khasanah dan Santi Hendriyeti. Judul: Tematik Terpadu Kurikulum 2013 Untuk SD/MI Kelas IV Cetakan ke-4, 2017 (Edisi Revisi). ${ }^{29}$ Adapun data sekunder berupa buku atau karya mengenai kekerasan simbolik dan gender perspektif Pierre Bourdieu. Berikut berupa buku yang terkait yakni pertama, Kekerasan Simbolik di Sekolah: Sebuah Ide Sosiologi Pendidikan Pierre Bourdieu, kedua, Reproduction in Education, Society and Culture, ketiga. Membaca Pemikiran Pierre Bourdieu, keempat. (Hobitus x Modal) + Praktik; Pengantar Paling

26 Jason D. Edgerton, Lance W. Roberts, dan Tracey Peter, "Disparities in Academic Achievement: Assessing the Role of Habitus and Practice," Social Indicators Research 114, no. 2 (2013): 303-322.

27 Agung Prihantoro dan Fattah Hidayat, "Melakukan Penelitian Tindakan Kelas," Ulumuddin: Jurnal Ilmu-ilmu Keislaman 9, no. 1 (2019): 49-6o.

28 Winarno Surakhmad, Pengantar penelitian ilmiah : dasar, metode dan teknik (Bandung: Tarsito, 2004), h. 140

29 Angi St. Anggari et al., Buku tematik terpadu kurikulum 2013, buku siswa $S D / M I$ kelas IV (Jakarta: Pusat Kurikulum dan Perbukuan, Balitbang, Kemendikbud, 2017). 
Komprehensif kepada Pemikiran Pierre Bourdieu. Kelima, An Innovation to Reflexive Sociology, Keenam, Arena Produksi Kultural; Sebuah Kajian Sosiologi Budaya, dan Ketujuh, Intelektual Kolektif pierre Boudiue; Sebuah Gerakan Untuk Melawan Dominasi. Selain itu ada jurnal, essay, internet, majalah, surat kabar, dan media informasi lainnya yang juga terkait dengan kekerasan simbolik.

\section{Hasil}

Berdasarkan pengelolaan data kelas gender dalam buku ajar, maka hasil penelitian menunjukkan adanya dominasi kelas gender pada kalimat dan gambar. Adapun rinciannya sebagai berikut:

Tabel 1 Habitus Kelas Gender pada Kalimat di Buku Ajar

\begin{tabular}{ccc}
\hline Tema & \multicolumn{2}{c}{ Kelas Gender } \\
& Perempuan & Laki-laki \\
\hline 1 & 5 & 3 \\
2 & 8 & 4 \\
3 & 8 & 6 \\
4 & 15 & 25 \\
5 & 4 & 24 \\
\hline Jumlah & 40 atau 39,2\% & 62 atau 61,8\% \\
\hline
\end{tabular}

Dari tabel 1 dapat dilihat secara akumulatif bahwa terjadi dominasi kelas gender pada kalimat di buku ajar. Di mana kelas laki-laki dominan yakni 61,8\% sedangkan kelas perempuan sebagai kelas yang terdominasi yakni 39,2\%. Dominasi tentu akan mengakibatkan adanya sosialisasi habitus kelas laki-laki yang sering muncul dalam buku ajar. Sehingga secara laten, sosialisasi habitus kelas laki-laki dijalankan untuk melanggengkan atau mereproduksi struktur sosial dan budaya kelas gender tertentu. Sehingga sadar laten habitus tersebut diyakini sebagai sesuatu yang dibenarkan dan diimitasi oleh peserta didik.

Tabel 2

Habitus Kelas Gender pada Gambar di Buku Ajar

\begin{tabular}{ccc} 
Tema & \multicolumn{2}{c}{ Kelas Gender } \\
& Perempuan & Laki-laki \\
\hline 1 & 11 & 10 \\
2 & 11 & 9 \\
3 & 7 & 9 \\
4 & 8 & 22 \\
5 & 5 & 28 \\
\hline
\end{tabular}




\begin{tabular}{lll}
\hline Jumlah & 42 atau $35 \%$ & 78 atau $65 \%$ \\
\hline
\end{tabular}

Dari tabel 2 dapat dilihat secara akumulatif bahwa terjadi dominasi kelas gender pada kalimat di buku ajar. Di mana kelas laki-laki dominan yakni 65\% sedangkan kelas laki-laki sebagai kelas yang terdominasi yakni 35\%. Dominasi tentu akan mengakibatkan habitus kelas laki-laki yang sering muncul tersosialisasikan melalui buku ajar. Sehingga secara tidak sadar habitus tersebut diyakini sebagai sesuatu yang dibenarkan dan diimitasi.

\section{Pembahasan}

Temuan penelitian menunjukkan kekerasan simbolik dalam buku ajar memang ada. Kekerasan simbolik yang halus dan laten dalam buku ajar digunakan untuk mendominasi kelas yakni kelas laki-laki terhadap kelas perempuan. Upaya dominasi tersebut digunakan untuk meligitimasi kelas dominan dalam rangka memaksakan pandangan dunia sosial yang dirasa benar oleh struktur sosial dan budaya kelas tertentu. Di mana secara tidak sadar, tujuan dominasi kelas tersebut untuk melanggengkan atau mereproduksi struktur sosial dan budayanya.

Bentuk dominasi terungkap dengan bahasa yakni berupa kalimat atau simbol yang berupa gambar. Bahasa merupakan produk budaya, yang tentu saja tidak dapat dipisahkan dari konteks sosialnya. Bahasa dapat mencerminkan "siapa penuturnya”. Bahasa mencerminkan pesan, dalam bahasa Bourdieu, pesan ini dinamakan sebagai simbol. Kelas dominan melalui bahasa, seolah-olah ingin memberitahukan kepada kelas terdominasi "inilah seleraku", "inilah habitusku", "inilah budayaku”. зо Bourdieu melihat relasi bahasa, pendidikan, dan budaya tidak dapat dipisahkan. kelas tertentu mencoba mendominasi melalui simbol dan sarana budaya dalam rangka melestarikan habitus mereka.

Pelestarian kelas gender di buku ajar tematik terpadu karya Angi St. Anggari dkk. pada kalimat dan gambar menghasilkan adanya distingsi kelas dominan dengan kelas yang terdominasi. Distingsi pada buku ajar menjadi akar yang mengakibatkan terjadinya ketimpangan. Ketimpangan

$3^{\circ}$ Martono, Kekerasan Simbolik, h.47. 
kondisi berupa perbedaan akses, partisipasi, kontrol, dan manfaat tergambar antara laki-laki dan perempuan yang merupakan salah satu isu gender. ${ }^{11}$ Dominasi kelas gender merupakan entitas ketimpangan pastisipasi antara kelas laki-laki dan kelas perempuan. Partisipasi kelas dominan dalam arena buku ajar merupakan bentuk pelestarian habitus yang mencoba untuk dilanggengkan. Secara implisit hal tersebut telah melahirkan entitas kekerasan simbolik.

Analisis buku tematik terpadu kurikulum 2013 edisi revisi 2017 untuk siswa kelas IV SD/MI karya Angi St. Anggari dkk. terdapat 9 tema yakni tema 1 "Indahnya Kebersamaan", tema 2 "Selalu Berhemat energi", tema 3 "Peduli Terhadap Makhluk Hidup”, tema 4 "Berbagai Pekerjaan”, tema 5 "Pahlawanku", tema 6 "Cita-citaku", tema 7 "Indahnya Keragamaan di Negeriku”, tema 8 "Daerah Tempat Tinggal", dan tema 9 “Kekayaan Negeriku”. Dari 9 tema dalam buku kelas IV tersebut, peneliti mencoba menganalisis tema 1, 2, 3, 4, dan 5 (semester 1 ) yang terindikasi adanya kekerasan simbolik pada kalimat dan gambar melalui komponen gender yakni peran kerja, kegemaran, sifat, dan status sosial.

Hasil analisis pada kalimat juga menunjukkan distingsi kelas lakilaki dan kelas perempuan. Di mana kelas laki-laki secara akumulatif lebih banyak disosialisasikan yakni 62 kalimat atau 61,8\% kalimat sedangkan kelas perempuan hanya 40 kalimat atau 39,2\% kalimat. Hal ini senada dengan penelitian yang dilakukan UNICEF yang menunjukkan jika buku ajar tingkat ibtidaiyah lebih menonjolkan anak laki-laki melalui beragam peran kreatif daripada perempuan. ${ }^{2}$ Banyaknya sosialisasi kelas laki-laki menunjukkan adanya dominasi kelas yakni kelas laki-laki dan ada kelas yang terdominasi yakni kelas perempuan. Pada kalimat terlihat ketimpangan yang ada disparitas besar yakni lebih dari 60\% pada tema 4 "Berbagai Pekerjaan" dan tema 5 "Pahlawanku". Pada tema 4 sosialisasi habitus kelas laki-laki terdapat 25 kalimat atau 62,5\% kalimat, sedangkan kelas perempuan hanya terdapat 15 kalimat atau 37\% kalimat. Pada tema 5

${ }^{1}$ Ismi Dwi Astuti Nurhaeni, Pedoman Teknis Penyusunan Gender Analysis Pathway (GAP) Dan Gender Budget Statement (GBS) (Jakarta: Australia Indonesia Partnership for Decentralisation, n.d.). ${ }^{32}$ Martono, Kekerasan Simbolik, h.7. 
sosialisasi habitus kelas laki-laki terdapat 24 kalimat atau 85,7\% kalimat, sedangkan kelas perempuan terdapat 4 kalimat atau 14,3\% kalimat. Sosialisasi habitus kelas laki-laki pada kalimat merupakan entitas pelanggengan atau reproduksi kebiasaan kontruksi sosial dan budaya yang dipaksakan untuk disepakati sebagai suatu yang dibenarkan dan diimitasi dalam kehidupan sosial. Secara laten, sosialisasi habitu kelas laki-laki sebagai kelas gender yang mendominasi dan kelas perempuan sebagai kelas yang terdominasi inilah melahirkan adanya kekerasan simbolik.

Hasil analisis pada gambar secara akumulatif pada semester 1 menunjukkan ada dominasi kelas laki-laki yakni terdapat 78 gambar atau 65\%, sedangkan kelas perempuan sebagai kelas terdominasi terdapat 42 kalimat atau 35\% gambar. Pada gambar terlihat ketimpangan yang ada disparitas besar yakni lebih dari 60\% pada tema 4 "Berbagai Pekerjaan" dan tema 5 "Pahlawanku". Pada tema 4 sosialisasi habitus kelas laki-laki terdapat 22 gambar atau 73,3\% gambar, sedangkan kelas perempuan hanya terdapat 8 gambar atau 26,7\% gambar. Pada tema 5 sosialisasi habitus kelas laki-laki terdapat 28 gambar atau 84,8\% gambar, sedangkan kelas perempuan terdapat 5 gambar atau $15,2 \%$ gambar. Sosialisasi habitus kelas laki-laki pada gambar merupakan entitas pelanggengan atau reproduksi kebiasaan kontruksi sosial dan budaya yang diterima dan diimitasi sebagai kebiasaan, selera, gaya hidup, sikap, perilaku yang dianggap baik dan hal tersebut diterima begitu saja sebagai hal biasa dalam kehidupan sosial.

Secara laten, buku ajar tematik terpadu kurikulum 2013 edisi revisi 2017 menjadi arena kesepakatan-kesepakatan para agen dalam hal ini pemilik kuasa yakni penulis buku, pemangku kebijakan atau penerbit untuk menjalankan konstruksi sosial dan budaya. Penjelasan Bourdieu selanjutnya, kekerasan itu dilembagakan lewat perantara kesepakatankesepakatan. Makna konsep kekerasan simbolik ini terletak pada upaya agen sosial dominan menerapkan suatu makna sosial dan representasi realitas yang diinternalisasi kepada agen lain sebagai sesuatu yang alami 
dan absah, bahkan makna sosial tersebut kemudian dianggap benar oleh aktor lain tersebut. 33

Pengakuan kebenarang digunakan untuk menjalankan tindakan pedagogis. Padahal tindakan itu telah mencerminkan kepentingan kelas dominan, yang cenderung mereproduksi distribusi modal kultural secara tidak merata antar kelas yang hidup dalam suatu ruang sosial, sehingga mereproduksi struktur sosial.34 Tindakan pedagogis menjadi alat legitimasi kelas dominan dalam hal ini kelas laki-laki untuk melestarikan budaya mereka, sehingga habitus mereka diterima oleh kelas terdominasi. Pelestarian budaya mengakibatkan terjadinya reproduksi kelas sosial dalam pendidikan. Dengan demikian sangat jelas, bahwa sekolah berfungsi untuk memproduksi ketidaksetaraan, ketimpangan partisipasi, dan kekerasan termasuk dalam gender.

\section{E. Kesimpulan}

Berdasarkan hasil pengelolaan data dan pembahasan, maka dapat disimpulkan bahwa buku ajar tematik terpadu kurikulum 2013 edisi revisi 2017 untuk siswa kelas IV SD/MI semester 1 (tema 1, 2, 3, 4, dan 5) secara laten telah terjadi kekerasan yang dalam bahasa Bourdieu disebut sebagai kekerasan simbolik. Hal itu terjadi karena ada sosialisasi habitus kelas dominan terhadap kelas terdominasi. Hal ini terjadi pada kalimat dan gambar pada buku ajar. Di mana pada kalimat terdapat dominasi kelas laki-laki yakni terdapat 62 kalimat atau 61,8\% kalimat sedangkan kelas perempuan hanya 40 kalimat atau 39,2\% kalimat. Pada gambar kelas lakilaki mendominasi yakni terdapat 78 gambar atau 65\%, sedangkan kelas perempuan sebagai kelas terdominasi terdapat 42 kalimat atau 35\% gambar. Dominasi tersebut disosialisasikan untuk kelanggengan atau reproduksi pada kebiasaan konstruksi sosial dan budaya. Semuanya kemudian diterima dan diimitasi oleh peserta didik sebagai kebiasaan, selera, gaya hidup, sikap, perilaku yang dianggap baik dan hal tersebut diterima begitu saja sebagai hal biasa dalam kehidupan sosial.

33 Ibid.

34 Jenkins Richard, Membaca Pemikiran Pierre Bourdieu (Yogyakarta: Kreasi Wacana, 2016), h. 158. 
Kepada pihak penulis dan penerbit buku agar memperhatikan konten dan isi buku ajar. Buku ajar harus bebas dari pelbagai macam bentuk kekerasan termasuk kekerasan simbolik. Buku ajar perlu menjadi wadah untuk terus mensosialisasikan keadilan dan berkesetaraan gender. Kepada pihak sekolah dan pendidik perlu cermat untuk memberikan rekomendasi buku ajar bagi peserta didik. Setiap detail konten dan isi buku ajar perlu dibaca dan dipahami secara kritis. Agar apa yang akan dikonsumsi peserta didik dari buku ajar tidak bertentangan dengan semangat anti kekerasan termasuk kekerasan simbolik serta mencerminkan sikap keadilan dan berkesetaraan gender.

\section{DAFTAR PUSTAKA}

Al-Nashr, M. Sofyan. "Kekerasan Simbolik dalam Buku Pelajaran Madrasah (Analisis Kritis Perspektif Pierre Bourdieu)." Universitas Islam Negeri Sunan Kalijaga, 2014.

Anggari, Angi St., Wulan Afriki, Dara Retno Puspitawati, Nuniek Khasanah, Lely Mifthachul, dan Santi Hendriyeti. Buku tematik terpadu kurikulum 2013, buku siswa SD/MI kelas IV. Jakarta: Pusat Kurikulum dan Perbukuan, Balitbang, Kemendikbud, 2017.

Badan Pusat Statistik Provinsi Jawa Tengah. "Jumlah Kekerasan berdasarkan Jenis Kekerasan yang Dialami oleh Anak (Usia 0-18 Tahun) Korban Kekerasan di Provinsi Jawa Tengah, 2019.” Last modified https://jateng.bps.go.id/statictable/2020/o7/21/1913/jumlahkekerasan-berdasarkan-jenis-kekerasan-yang-dialami-oleh-anakusia-o-18-tahun-korban-kekerasan-di-provinsi-jawa-tengah-2019.html.

Bagus, Mukhtar. "Buku Agama Ajarkan Kekerasan, Banser Datangi Disdik Jombang." sindonews. Last modified 2015. Diakses September 1, 2020. https://daerah.sindonews.com/berita/980224/23/bukuagama-ajarkan-kekerasan-banser-datangi-disdik-jombang.

Bourdieu, Pierre, dan Loïc J. D. Wacquant. An Invitation to Reflexive Sociology. Cambridge: The University of Chicago Press, 1992.

D.J., Goodman, dan George Ritzer. Teori Sosiologi; dari Teori Sosiologi Klasik Sampai Perkembangan Mutakhir Teori Sosial Postmodern. Yogyakarta: Kreasi Wacana, 2017.

Edgerton, Jason D., Lance W. Roberts, dan Tracey Peter. "Disparities in Academic Achievement: Assessing the Role of Habitus and Practice." Social Indicators Research 114, no. 2 (2013): 303-322.

Eva Setya Rini. "Pendidikan Anti Kekerasan Terhadap Anak Berdasarkan Perspektif Islam (Al-Qur'an Dan Al-Hadits).” In Prosiding Seminar Nasional STKIP Andi Matappa Pangkep, 1:136-145, 2018.

Fatihah, Nurul, dan Difla Nadjih. "Hubungan Pendidik Dan Terdidik Dalam Al-Quran.” Ulumuddin: Jurnal Ilmu-ilmu Keislaman 7, no. 
2 (2017): 73-86.

Jauhari, Muhammad Insan. "Pendidikan Anti Kekerasan Perspektif AlQur'an Dan Implementasinya Dalam Metode Pengajaran PAI." Jurnal Pendidikan Agama Islam 13, no. 2 (April 24, 2017): 171184 .

Jenkins, Richard. Membaca Pemikiran Pierre Bourdieu. Yogyakarta: Kreasi Wacana, 2016.

Krais, Beate, dan Jennifer Marston William. "The Gender Relationship in Bourdieu's Sociology." SubStance 29, no. 3 (2000): 53-66.

Maradewa, Rega. "ajarkan kekerasan pada anak buku ini dilarang beredar." 2016. Diakses September 1, 2020. https://poskotanews.com/2016/o1/22/ajarkan-kekerasan-padaanak-buku-ini-dilarang-beredar/.

- - . "KPAI: 67 Persen Kekerasan Bidang Pendidikan Terjadi di Jenjang SD.” Last modified 2019. Diakses September 1, 2020. https://www.kpai.go.id/berita/kpai-67-persen-kekerasan-bidangpendidikan-terjadi-di-jenjang-sd.

Martono, Nanang. Kekerasan Simbolik di Sekolah: Sebuah Ide Sosiologi Pendidikan Pierre Bourdieu. Jakarta: Raja Grafindo Persada, 2012.

McNay, Lois. "Gender, Habitus and the Field: Pierre Bourdieu and the Limits of Reflexivity." Theory, Culture \& Society 16, no. 1 (1999): 95-117.

Munif, Muhammad, dan Siti Aisah. "Six Medicine Qoulan Dalam Mengatasi Kekerasan Guru Terhadap Siswa Di Lembaga Pendidikan.” Jurnal Inspiratif Pendidikan IX, no. 2 (Agustus 7, 2020): 35-52.

Nugraha, Muhamad Tisna. "Pendidikan Agama dan Kekerasan pada Anak (Child Abuse) Perspektif Pendidikan Islam.” Raheema 2, no. 1 (2015): 56-65.

Nugroho, Taufik. "Analisis Manajemen Pendidikan Terhadap Kualitas Madrasah Indonesia.” Ulumuddin: Jurnal Ilmu-ilmu Keislaman 6, no. 2 (2016): 80-87.

Nurhaeni, Ismi Dwi Astuti. Pedoman Teknis Penyusunan Gender Analysis Pathway (GAP) Dan Gender Budget Statement (GBS). Jakarta: Australia Indonesia Partnership for Decentralisation, n.d.

Prihantoro, Agung, dan Fattah Hidayat. "Melakukan Penelitian Tindakan Kelas.” Ulumuddin: Jurnal Ilmu-ilmu Keislaman 9, no. 1 (2019): 49-6o.

Putri, Rina Oktafia. "Praktek Kekerasan Simbolik (Relasi Guru dan Peserta didik dalam Pendidikan Islam).” Millah: Jurnal Studi Agama 17, no. 2 (April 5, 2018): 319-336.

Rahmawati, Arum Yuli Dwi, Muh Nasruddin, dan Imroatun Imroatun. "Peran Sosial Guru Pendidikan Agama Islam Di Wilayah Pesisir Utara Pulau Jawa." Nuansa Akademik Jurnal Pembangunan Masyarakat 5, no. 1 (Juni 16, 2020): 1-12.

Rubini. "Pendidikan Anti Kekerasan Dalam Al-Qur'an.” Al-Manar Jurnal Komunikasi dan Pendidikan Islam 7, no. 2 (Desember 30, 2018): 133-152.

Santoso, Fattah Setiawan. "Lingkungan Keluarga Sebagai Awal 
Pengembangan Kewirausahaan Islam.” Nuansa Akademik Jurnal Pembangunan Masyarakat 5, no. 1 (2020): 13-22.

Sulistiyo, Rozib. "Pengembangan Kecerdasan Emosional Bagi Siswa Kelas Awal Madrasah Ibtidaiyyah Pada Pembelajaran Bahasa Indonesia." Ulumuddin: Jurnal Ilmu-ilmu Keislaman 7, no. 1 (2017): 45-58.

Surakhmad, Winarno. Pengantar penelitian ilmiah : dasar, metode dan teknik. Bandung: Tarsito, 2004.

Suryanti, Dewi. "Kekerasan Simbolik Tayangan Drama Seri Korea Terhadap Perilaku Remaja Asrama Putri Kabupaten Kutai Timur.” eJournal Sosiatri/Sosiologi 4, no. 2 (2016).

Yuliantoro, Moch Najib. Ilmu dan Kapital: Sosiologi Ilmu Pengetahuan Pierre Bourdieu. Yogyakarta: Penerbit Kanisius, 2016. 